\title{
Total Endoscopic Transcanal Cartilage Myringoplasty: A Prospective Study
}

\author{
Dipesh Shakya ${ }^{1 \odot}$ Arun KC ${ }^{2}$ Ajit Nepal ${ }^{2}$ Nirmala Tamang ${ }^{3}$ \\ ${ }^{1}$ Department of Ear Nose and Throat, Civil Service Hospital, \\ Minbhawan Kathmandu, Kathmandu, Nepal \\ ${ }^{2}$ Department of Otorhinolaryngology, Patan Academy of Health \\ sciences, Lalitpur, Nepal \\ ${ }^{3}$ Department of Otorhinolaryngology, Civil Service Hospital, \\ Kathmandu, Nepal
}

\begin{abstract}
Address for correspondence Dipesh Shakya, MD, MS, Department of ENT, Civil Service Hospital, Minbhawan Kathmandu, Kathmandu 44600, Nepal (e-mail: dipeshent@yahoo.com).
\end{abstract}

Int Arch Otorhinolaryngol 2019;23:e440-e444.

\begin{abstract}
Introduction Middle ear surgeries, including myringoplasty, have increasingly utilized endoscopes as an adjunct to or as a replacement for the operative microscope. Objectives The objective of the present study was to evaluate the graft uptake rate and to evaluate the hearing results.

Methods This is a prospective study. We have analyzed 139 patients who underwent surgery for chronic otitis media (COM) of the mucosal type. All of the surgeries were performed exclusively under total endoscopic transcanal approach using tragal cartilage as graft, underlay technique. We have evaluated the postoperative graft uptake and performed a hearing evaluation at 6 weeks, at 12 weeks, and at 6 months. Results During the study period, 139 patients were included, out of which 13 were lost to follow-up; therefore, only 126 patients were assessed. All of the cases were performed under total endoscopic approach. As for the surgical outcome at the postoperative otoscopy, 3 cases had initial uptake at 3 months and failed later; therefore, complete closure of the perforation was observed in $97.6 \%(n=123)$ of the patients 6 months after the intervention.

Four patients presented with preoperative anacusis; therefore, only 122 patients were included for hearing evaluation. The preoperative air conduction threshold (ACT) and airbone gap (ABG) were $43.34 \pm 11.53$ and $24.73 \pm 7.89$, respectively.

Postoperatively, the ACT and ABG closure were $28.73 \pm 15.75$ and $11.91 \pm 8.41$,

Keywords

- cartilage

- endoscope

- myringoplasty respectively. This difference was statistically significant $(p<0.001)$.

Conclusion The endoscopic approach for myringoplasty offers excellent visualization; avoids postaural approach, enables a faster recovery, requires less hospital stay, with excellent graft closure rate and improved functional outcomes.
\end{abstract}

\section{Introduction}

Myringoplasty is the surgical procedure that is performed for the repair and closure of the perforation of the pars tensa of the tympanic membrane, and is the most common surgical procedure performed in chronic otitis media (COM) of the mucosal

received

January 24, 2019

accepted

April 4, 2019
DOI https://doi.org/

10.1055/s-0039-1691758. ISSN $1809-9777$. type. ${ }^{1}$ The main aim of this procedure is to decrease the infection, to prevent recurrent discharge, and to improve hearing. ${ }^{2}$

Though the temporalis fascia is still being used as graft material, it has been largely replaced by cartilage due to its stability and long-term uptake result. ${ }^{3}$

Copyright @ 2019 by Thieme Revinter

Publicações Ltda, Rio de Janeiro, Brazil

License terms

(1) $\ominus \circledast$ 
Microscopy has been considered to be the standard for ear surgery; however, endoscopic ear surgery is now widely accepted for many middle ear procedures. The use of endoscope in ear surgery was first reported in the early 1990s and since then its use has been broadened than before. ${ }^{4}$

The main advantage of endoscopes in myringoplasty is its wider field of view, including the anterior margins, which might be compromised with microscopes. ${ }^{5}$ Endoscopes provide much information about the eustachian tube orifice, the incudostapedial joint, the round window niche, the sinus tympani, and the hypotympanum. ${ }^{6}$ It can be used to perform less invasive surgery, avoiding canaloplasty, allowing a faster recovery, less pain, a better cosmetic outcome, and a shorter hospital stay. The objectives of the present study were to evaluate the graft uptake rate, to evaluate the hearing results, and to compare the pre- and postoperative hearing results

\section{Methods}

We have prospectively analyzed 139 patients who underwent surgery for COM of the mucosal type in our hospital from December 2016 to April 2017. Out of 139 cases, 13 patients were lost to follow-up; therefore, only 126 patients were included. Patients presenting with cholesteatoma, retraction pockets, or atelectasis were excluded from the study.

Patients aged $<13$ years old were operated under general anesthesia, and patients $\geq 13$ years old were operated under local anesthesia. The cases done under local anesthesia were not admitted and discharged on the same day. Ethical clearance was obtained from the Institutional Review Board. A local antibiotic and steroid treatment was performed in case of preoperative inflammation of the tympanic cavity. All surgeries were done via total transcanal approach, using a 0 degree, $4 \mathrm{~mm}, 18 \mathrm{~cm}$ rigid scope (Stryker 1488, Plymouth, MN, USA). A tragal cartilage graft was harvested, and the perichondrium was removed on both sides. The margin of perforation was refreshed, and the drum remnant was removed from the handle of the malleus. The mobility of the ossicular chain was checked. The graft was shaped to the size of the perforation. Gelfoams (SPONGOSTAN ${ }^{\mathrm{TM}}$ Special, Ferrosan Medical Devices A/S, Soeborg, Denmark were kept in the middle ear accordingly. For the posterior perforation, the graft was placed in the underlay technique, medial to the handle of the malleus, to the tympanic membrane, and to the annulus. For the central, anterior and subtotal perforation, the graft was notched to fit the handle of the malleus and was placed in the overunderlay technique. All of the cases were then reinforced using the perichondrium. The tympanomeatal flap was pulled down and the annulus was meticulously inserted in the sulcus. The external auditory canal (EAC) was packed with gelfoam and then with ear pack (Osseous Ear pack, EonMeditech pvt Itd., Gujarat, India), which was removed after 7 days. (-Figs. 1-5)

The patients were followed up at 6 weeks, at 12 weeks, and at 6 months. The average on 4 frequencies $(0.5,1,2$ and 3 $\mathrm{kHz}$ ) of hearing thresholds in air and bone conduction and in the air bone gap $(A B G)$ were been evaluated 7 days before the surgery and 12 weeks postsurgery.

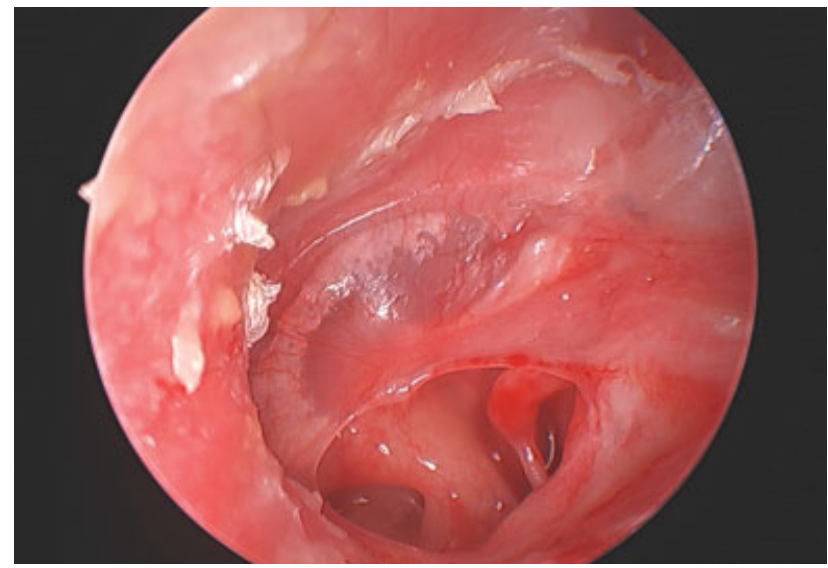

Fig. 1 Preoperative perforation.

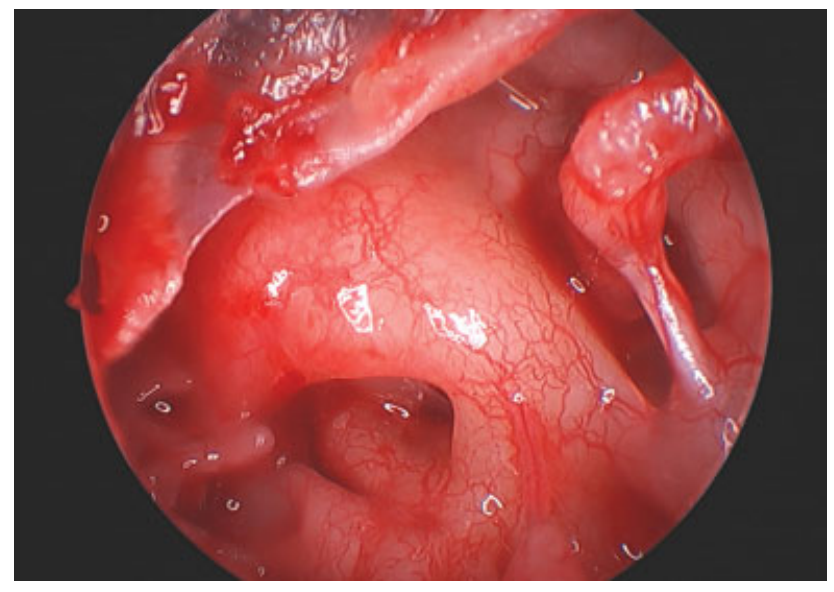

Fig. 2 Middle ear and ossicles exposed.

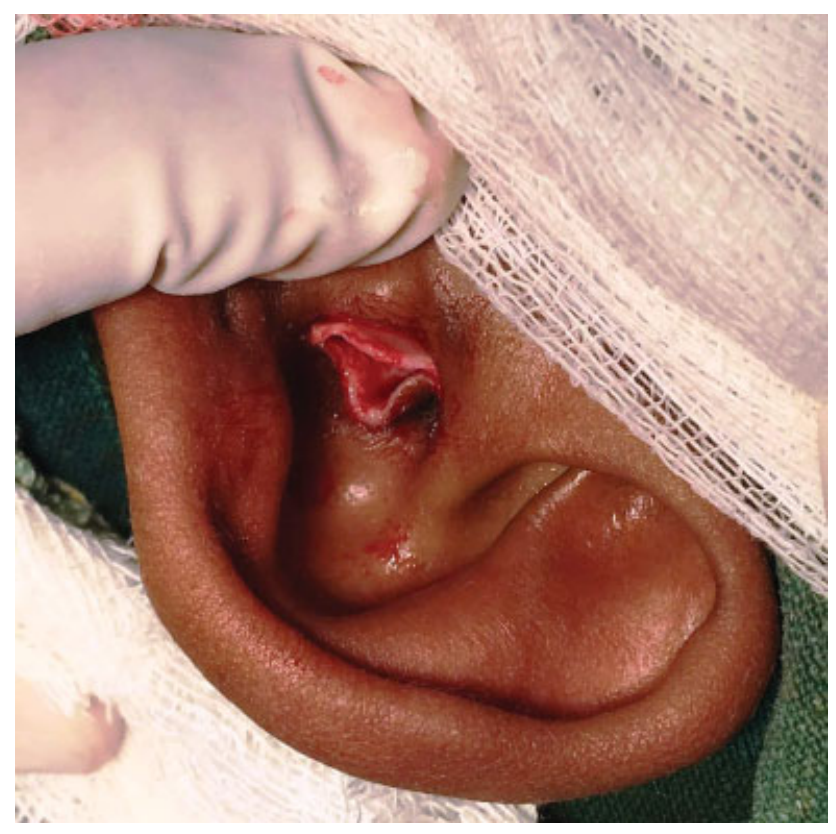

Fig. 3 Graft harvested. 


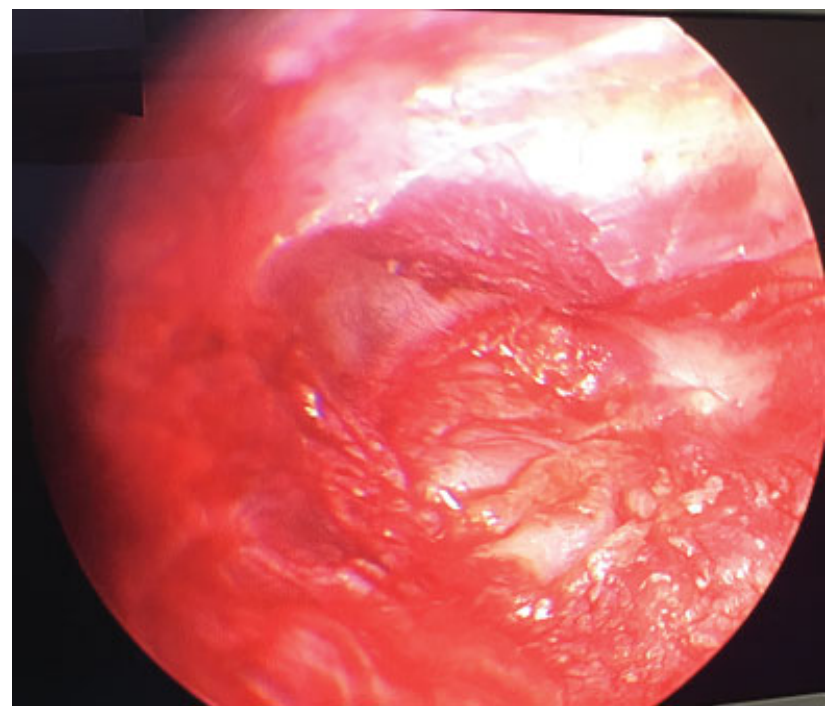

Fig. 4 Graft placed.

\section{Results}

During the study period, 139 patients were included, out of which 13 were lost to follow-up; therefore, only 126 patients were assessed. The mean age of the patients was $28 \pm 11.21$ old. Their age ranged from 7 to 64 years old. There were 50 (39.7\%) males and 76 females (60.3\%). As for the laterality, in $53(42.1 \%)$ patients the operation was performed on the right side, and in 73 (57.9\%) patients the operation was performed on the left side. Most of the patients were undergoing surgery for the $1^{\text {st }}$ time; patients undergoing revision surgery accounted for $2.3 \%$ of the cases $(n=3)$.

There were no cases that required surgical conversion to the retroauricular approach or to the use of the microscope in this series. All of the cases were performed under total endoscopic approach. As for the surgical outcome at the postoperative otoscopy, 3 cases presented initial uptake at 3 months and failed later; therefore, complete closure of the perforation was observed in $97.6 \%(n=123)$ of the patients 6 months after the intervention.

Audiometrically, an improvement in the pure tone average (PTA) hearing thresholds was observed from the preoperative to the postoperative period (-Table 1 and $\mathbf{2}$ ). Four patients had preoperative anacusis; therefore, only 122 patients were included for hearing evaluation. The preopera-

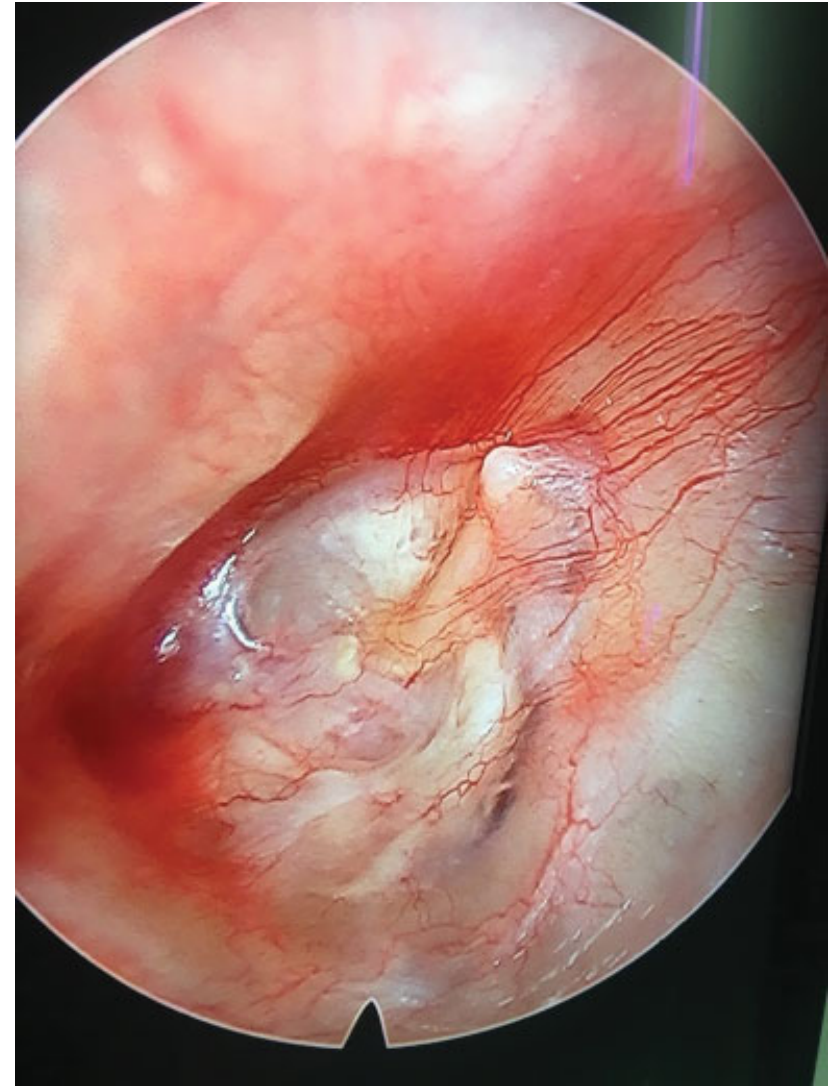

Fig. 5 Graft uptake after 6 months.

tive air conduction threshold (ACT) and the airbone gap (ABG) closure were $43.34 \pm 11.53$ and $24.73 \pm 7.89$ respectively. Postoperatively, the ACT and the ABG closure were $28.73 \pm 15.75$ and $11.91 \pm 8.41$, respectively. This difference was statistically significant $(p<0.001)$. A total of $60 \%$ of the cases had a preoperative $A B G$ level of between 21 and $30 \mathrm{~dB}$, and the postoperative $A B G$ had a maximum of $67 \%$, which fell $<$ between 0 and $10 \mathrm{~dB}$.

\section{Discussion}

Myringoplasty is conventionally performed using a microscope, since it provides stereoscopic vision and better depth perception along with bimanual handling. ${ }^{7}$ The use of an endoscope for treating ear diseases has been dated since the 1960s. ${ }^{8}$

Table 1 Pre- and Postoperative hearing outcomes

\begin{tabular}{|l|l|l|l|l|}
\hline \multicolumn{2}{|c|}{} & Mean & $n$ & Standard deviation \\
\hline \multirow{3}{*}{ Pair 1 } & Preoperative ACT & 43.3420 & 122 & 11.53721 \\
\cline { 2 - 5 } & Postoperative ACT & 28.7377 & 122 & 15.75454 \\
\hline \multirow{2}{*}{ Pair 2 } & Preoperative BCT & 18.6066 & 122 & 8.87266 \\
\cline { 2 - 5 } & Postoperative BCT & 16.8238 & 122 & 8.81564 \\
\hline Pair 3 & Preoperative ABG & 24.7354 & 122 & 7.89815 \\
\cline { 2 - 5 } & Postoperative ABG & 11.9139 & 122 & 8.41264 \\
\hline
\end{tabular}

Abbreviations: $A B G$, airbone gab; $A C T$, air conduction threshold; $B C T$, bone conduction threshold. 
Table 2 Airbone gap range

\begin{tabular}{|c|c|c|c|c|c|}
\hline & & \multicolumn{2}{|c|}{ Preoperative hearing } & \multicolumn{2}{|c|}{ Postoperative hearing } \\
\hline & & Frequency & $\%$ & Frequency & $\%$ \\
\hline \multirow[t]{6}{*}{ Airbone gap } & $0-10$ & 3 & 2.5 & 67 & 54.9 \\
\hline & $11-20$ & 36 & 29.5 & 39 & 32.0 \\
\hline & $21-30$ & 60 & 49.2 & 8 & 6.6 \\
\hline & $31-40$ & 19 & 15.6 & 7 & 5.7 \\
\hline & $>40$ & 4 & 3.3 & 1 & 0.8 \\
\hline & Total & 122 & 100.0 & 122 & 100.0 \\
\hline
\end{tabular}

The $1^{\text {st }}$ reported case of endoscopic myringoplasty was by el-Guindy in $1992 .{ }^{9}$ There are now numerous studies published on endoscopic ear surgery with graft uptake rate comparable to microscopic ear surgery. In our study, we had a graft uptake rate of $97.6 \%$. There was a statistically significant improvement in hearing outcome, with ABG improvement of $11.9 \pm 8.4$. Almost $50 \%$ of the patients had a preoperative $A B G$ ranging between 21 and $30 \mathrm{~dB}$, which resulted in the closure of the $A B G(0-10 \mathrm{~dB})$ in $54.9 \%$ of the patients after the surgery.

The present study is comparable to the study performed by Ayache. ${ }^{10}$ His study had an uptake rate of $96 \%$ in the 1 year follow-up period performed in 30 cases. Similary, Huang et al had an uptake rate of $98 \%$ in 6 months of followup using endoscopic cartilage myringoplasty in 50 cases. His study had a hearing improvement of $8.9 \mathrm{~dB}$ in the $\mathrm{ABG}{ }^{7}$ Karhuketo et al had a closure rate of $90 \%$ in 29 cases in 1 year of follow-up, and the postoperative ABG was $<10$ $\mathrm{dB}$ in $90 \%$ of the ears. ${ }^{11}$ Mokbel et al had a graft uptake rate of $100 \%$ in type I cartilage tympanoplasty in 40 ears with a follow-up ranging between 6 and 24 months. He had a postoperative hearing improvement of the $A B G$ of $8.50 \pm 1.25 \mathrm{~dB} .{ }^{12}$ A similar result was also obtained by Singh et al, with a closure rate of $92.85 \%$ in 28 ears at 2 years of follow-up. They had an average postoperative ABG of $15.65 \mathrm{~dB} .{ }^{13}$ Özgür et al had an uptake rate of $92.5 \%$ in 53 ears at 6 months of follow-up with improvement in hearing, with a postoperative $\mathrm{ABG}$ of $10 \pm 7 \mathrm{~dB} .^{8}$ All of our cases were performed exclusively by the transcanal approach using an endoscope, and we did not need to use a microscope nor the postaural or the endaural approach. Because of the wide view of the endoscope, all of the margins of the perforation could be visible. This provided the benefit of faster patient recovery, shorter hospital stay, and less financial burden to the patient.

However, there are several disadvantages of endoscopic ear surgery. It requires the surgeon to use only one hand, sometimes the instrument gets crowded, and at times it gets contaminated with bleeding. This required learning curve to overcome. It provides two-dimensional vision, impairing depth perception; however, now this has been overcome by high-definition camera systems. ${ }^{7}$ Two main safety concerns of endoscopic ear surgery are excessive heat dissipation, and accidental movement of the patient, with secondary direct trauma caused by the tip of the endoscope, which has been explained nicely by Tarabichi in his article. ${ }^{14}$ We did not experience any trauma caused by the endoscope in our study period. All of the patients were discharged on the same day. No sutures were applied. The short follow-up period is one of the limitations of the present study.

\section{Conclusion}

The endoscopic approach for myringoplasty offers excellent visualization, avoids the postaural approach, enables a faster recovery, and requires a shorter hospital stay, with excellent graft closure rate and improved functional outcome.

Being of a low set-up cost, of easy portability and handling, endoscopic surgery holds promising results to be applied in developing countries like ours.

Conflicts of Interests

The authors have no conflicts of interests to declare.

\section{References}

1 Aggarwal R, Saeed SR, Green KJ. Myringoplasty. J Laryngol Otol 2006;120(06):429-432

2 Browning GG, Merchant SN, Kelly G, Swan IR, Canter R, McKerrows WS. Chronic otitis media. Scotts-Brown's Otorhinolaryngology, Head and Neck Surgery, 7th edition. London: Edward Arnold publisher Ltd.; 2008:3395-3445

3 Beutner D, Huttenbrink KB, Stumpf R, et al. Cartilage plate tympanoplasty. Otol Neurotol 2010;31(01):105-110

4 Bernardeschi D, Lahlou G, De Seta D, Russo FY, Mosnier I, Sterkers O. 3D endoscopic ear surgery: a clinical pilot study. Eur Arch Otorhinolaryngol 2018;275(02):379-384

5 Mohanty S, Manimaran V, Umamaheswaran P, Jeyabalakrishnan $\mathrm{S}$, Chelladurai S. Endoscopic cartilage versus temporalis fascia grafting for anterior quadrant tympanic perforations - A prospective study in a tertiary care hospital. Auris Nasus Larynx 2018;45 (05):936-942

6 Marchioni D, Molteni G, Presutti L. Endoscopic anatomy of the middle ear. Indian J Otolaryngol Head Neck Surg 2011;63(02):101-113

7 Huang TY, Ho KY, Wang LF, Chien CY, Wang HM. A Comparative Study of Endoscopic and Microscopic Approach Type 1 Tympanoplasty for Simple Chronic Otitis Media. J Int Adv Otol 2016;12 (01):28-31

8 Özgür A, Dursun E, Erdivanli ÖÇ, et al. Endoscopic cartilage tympanoplasty in chronic otitis media. J Laryngol Otol 2015; 129(11):1073-1077

9 el-Guindy A. Endoscopic transcanal myringoplasty. J Laryngol Otol 1992;106(06):493-495 
e444 Total Endoscopic Transcanal Cartilage Myringoplasty Shakya et al.

10 Ayache S. Cartilaginous myringoplasty: the endoscopic transcanal procedure. Eur Arch Otorhinolaryngol 2013;270(03): 853-860

11 Karhuketo TS, Ilomäki JH, Puhakka HJ. Tympanoscope-assisted myringoplasty. ORL J Otorhinolaryngol Relat Spec 2001;63(06): 353-357, discussion 358

12 Mokbel KM, Moneir W, Elsisi H, et al. Endoscopic Transcanal Cartilage Myringoplasty for Repair of Subtotal Tympanic Mem- brane Perforation: A Method to Avoid Postauricular Incision. J Otolaryngol Rhinol. 2015;1:2

13 Singh R, Kundu S, Sarkar S, Ghosh B, Mukhopadhyay S. Comparative study of endoscopic temporalis fascia versus endoscopic cartilage tympanoplasty. Bengal J Otolaryngol Head Neck Surg 2013;21:16-17

14 Tarabichi M. Endoscopic transcanal middle ear surgery. Indian J Otolaryngol Head Neck Surg 2010;62(01):6-24 